\title{
Hypoglycaemia Among Insulin-Treated Patients with Diabetes \\ Evaluation of the United Arab Emirates cohort of the International Operations-Hypoglycaemia Assessment Tool study
}

Salah Abusnana, ${ }^{1}$ "Salem A. Beshyah, ${ }^{2,3}$ Nawal Al-Mutawa, ${ }^{4}$ Rima Tahhan, ${ }^{5}$ Mahir Jallo, ${ }^{6}$ Ravi Arora, Hazem Aly, ${ }^{8}$ Sagar Singhal ${ }^{8}$

$$
\begin{aligned}
& \text { هبوط سكر الدم بين مرضى السكر الذين يتلقون علاجحاً بالإنسولين } \\
& \text { بحموعة الإمارات العربية المتحدة لدراسة أداة تقييم هبوط سكر الدم في العمليات الدولية }
\end{aligned}
$$

صلاح أبوسنانة، سالم بشيه، نوال المطوع، ريما طحان، ماهر جلو، رافي أرورا، حازم علي، ساجار سنغال

ABSTRACT: Objectives: This study aimed to evaluate the incidence of hypoglycaemia among insulin-treated patients with type 1 diabetes mellitus (T1DM) or type 2 diabetes mellitus (T2DM) from the United Arab Emirates (UAE) cohort of the non-interventional International Operations-Hypoglycaemia Assessment Tool study. Methods: This cross-sectional observational study took place at 25 patient care centres in the UAE from October 2014 to May 2015. All adult patients with T1DM or T2DM who had been treated with insulin for $>12$ months were included. Self-assessment questionnaires and patient diaries were used to determine the incidence of documented hypoglycaemia both prospectively (four weeks after baseline) and retrospectively (six months and four weeks before baseline for severe and non-severe hypoglycaemic events, respectively). Results: A total of 325 patients were enrolled in the study, of which 82 (25.2\%) had T1DM and 243 (74.8\%) had T2DM. Among patients with T1DM, 71.4\% reported hypoglycaemic events retrospectively, with an incidence rate (IR) of 102.8 events per patient-year (PY), while 95\% reported hypoglycaemic events prospectively, with an IR of 63.1 events per PY. Additionally, 56.3\% of patients with T2DM reported hypoglycaemic events retrospectively, with an IR of 42.2 events per PY, while 91.9\% reported hypoglycaemic events prospectively, with an IR of 33.3 events per PY. Conclusion: The prevalence and incidence of hypoglycaemia were high among insulin-treated patients with T1DM and T2DM in the UAE. Individualised glycaemic goals, patient education and blood glucose monitoring may help to reduce the incidence of hypoglycaemia in this population.

Keywords: Hypoglycemia; Insulin; Type 1 Diabetes Mellitus; Type 2 Diabetes Mellitus; United Arab Emirates.

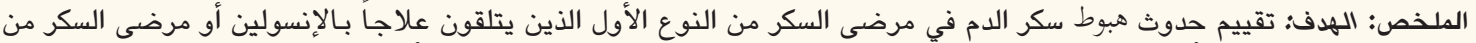

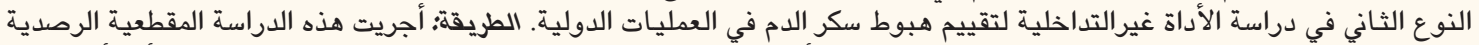

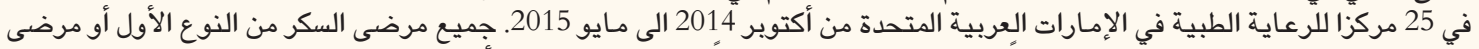

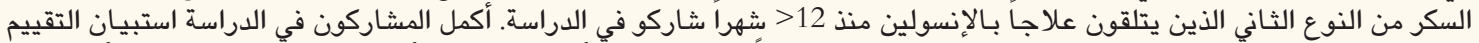

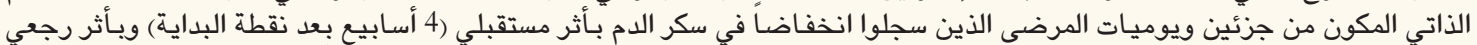

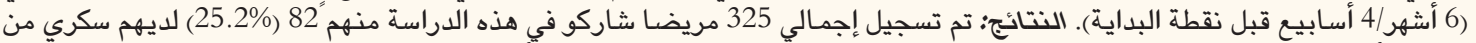

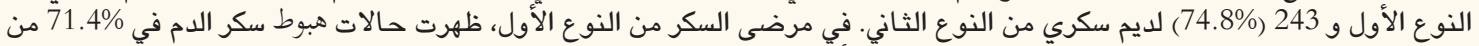

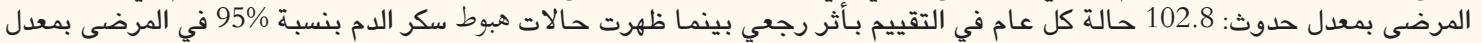

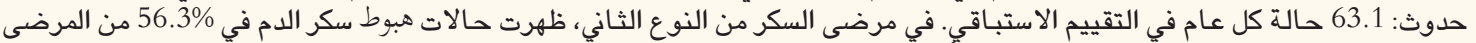

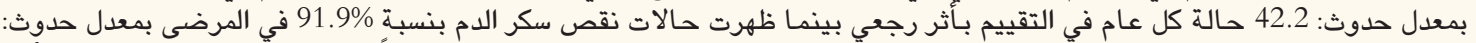

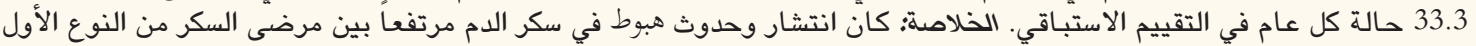

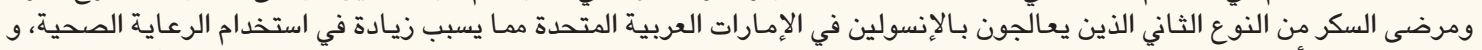

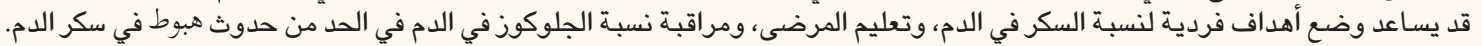
الكلمات المفتاحية؛ هبوط سكر الدم؛ إنسولين؛ مرض السكر من النوع الأول؛ مرض السكر من النوع الثاني؛ الإمارات العربية المتحدة.

\section{AdvanCES IN KNOWLEDGE}

To the best of the authors' knowledge, this study is the first patient-reported dataset regarding the incidence of hypoglycaemia in the United Arab Emirates (UAE) cohort of the International Operations-Hypoglycaemia Assessment Tool study.

\section{Application to Patient Care}

Knowledge regarding the real-world incidence rate of hypoglycaemic events may help patients and healthcare providers to effectively manage the disease, reducing its clinical and economic burden and improving healthcare resource utilisation. 
$\mathrm{H}$ YPOGLYCAEMIA IS A CONDITION IN WHICH blood glucose (BG) levels drop below normal levels (3.9-7.1 mmol/L). ${ }^{1}$ Approximately $90 \%$ of all patients treated with insulin experience hypoglycaemic episodes/events. ${ }^{2}$ Complex regimes and glycaemic restrictions have been shown to increase the risk of hypoglycaemia, with severe hypoglycaemic events associated with increased mortality and morbidity. ${ }^{3}$ Hypoglycaemia also carries an economic burden, impacting patient productivity and disease management and utilising valuable healthcare resources. ${ }^{4}$

According to a recent meta-analysis, hypoglycaemia is prevalent among patients with type 2 diabetes mellitus (T2DM), thus necessitating an individualised approach to treatment and patient education. ${ }^{5}$ The Canadian Hypoglycaemia Assessment Tool Program revealed high rates of hypoglycaemia among insulin-treated patients; the researchers advocated for the identification of high-risk insulin-treated patients in order to reduce the incidence of hypoglycaemia in this patient group. ${ }^{6}$ In Germany, a patient-reported study revealed high rates of nonsevere hypoglycaemic events among those with type 1 diabetes mellitus (T1DM) or insulin-treated T2DM. ${ }^{7}$ Unfortunately, it can be difficult to establish the actual rate of hypoglycaemic events as the majority of published data are based on the results of randomised controlled clinical trials (RCTs), which usually investigate the clinical efficacy and safety of certain drugs. ${ }^{89}$ Moreover, patients at higher risk of hypoglycaemia are often excluded from RCTs. ${ }^{10}$

In 2017, the International Operations-Hypoglycaemia Assessment Tool (IO-HAT) study was conducted to determine the prevalence and incidence rates (IRs) of hypoglycaemic events among 7,289 insulin-treated patients with T1DM and T2DM in Bangladesh, Colombia, Egypt, Indonesia, the Philippines, Singapore, South Africa, Turkey and the United Arab Emirates (UAE). ${ }^{11}$ The IO-HAT study was itself based on data gathered as part of a larger investigation of 27,585 adult patients from 24 countries. ${ }^{12}$ The current study aimed to determine the incidence of hypoglycaemia among the UAE cohort of the IO-HAT study. ${ }^{11}$ In addition, the patients' knowledge of and attitudes towards hypoglycaemia were assessed, as well as the relationship between the incidence of hypoglycaemia and insulin regimens and glycaemic control, as determined by baseline glycated haemoglobin (HbA1c) measurements.

\section{Methods}

This cross-sectional non-interventional study was conducted at 25 patient care centres in the UAE between October 2014 and May 2015. All patients with T1DM or T2DM who were $\geq 18$ years old at baseline and who had been treated with an insulin regimen for $>12$ months were included. Patients were enrolled in the study according to a consecutive sampling method during routine clinical consultation with their healthcare providers. As per the guidelines of the American Diabetes Association, severe hypoglycaemia was defined as an event of confirmed hypoglycaemia requiring the assistance of another individual to actively administer carbohydrate or glucagon interventions or take resuscitative action. ${ }^{13}$ Non-severe events were defined as symptomatic events not requiring biological confirmation and managed by the patient alone. Nocturnal hypoglycaemia was defined as an event occurring between midnight and 6 AM. $^{13}$

Self-reported events of hypoglycaemia were documented by participants using a two-part self-assessment questionnaire and patient diaries. The primary endpoint of the study was the percentage of patients experiencing at least one hypoglycaemic event during a four-week prospective period; events were recorded in patient diaries completed over a four week period from baseline. The secondary endpoints included the IRs of hypoglycaemia prospectively (four weeks after baseline) and retrospectively (six months and four weeks before baseline for severe and non-severe events, respectively); these were determined according to a two-part selfassessment questionnaire, with the first part completed by the participants at baseline and the second part completed four weeks later [Figure 1]. The two-part self-assessment questionnaire and patient diaries were translated into local languages and all acquired data were subsequently translated back into English for analytical purposes.

Other secondary endpoints included the patients' knowledge, awareness and fear of and attitudes towards hypoglycaemia and the relationship between the incidence of hypoglycaemia and insulin regimens and gly-

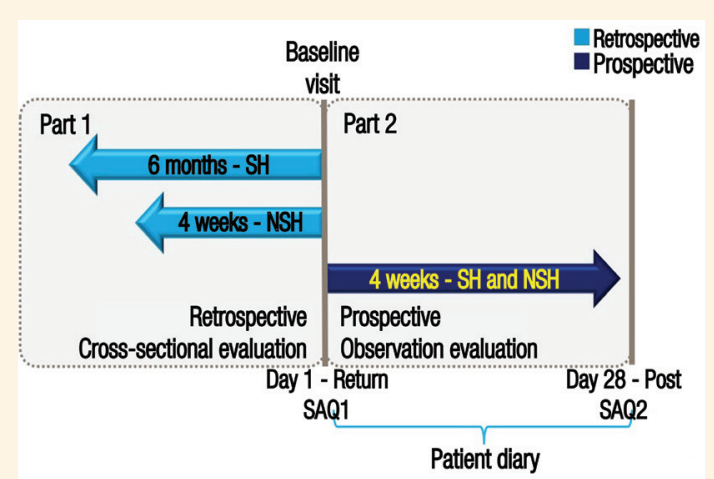

Figure 1: Diagram illustrating the design of the study. $\mathrm{SH}=$ severe hypoglycaemia; $\mathrm{NSH}=$ non-severe hypoglycaemia; $S A Q=$ self-assessment questionnaire.

Figure adapted with permission from: Emral R, Pathan F, Cortés CA, El-Hefnawy MH, Goh SY, Gómez AM, et al. Self-reported hypoglycemia in insulin-treated patients with diabetes: Results from an international survey on 7289 patients from nine countries. ${ }^{11}$ 
Table 1: Characteristics of insulin-treated patients with type 1 and type 2 diabetes mellitus in the United Arab Emirates $(\mathrm{N}=325)$

\begin{tabular}{|c|c|c|}
\hline \multirow[t]{2}{*}{ Variable } & \multicolumn{2}{|c|}{ n (\%) } \\
\hline & $\begin{array}{l}\text { T1DM patients } \\
\quad(\mathrm{n}=82)\end{array}$ & $\begin{array}{l}\text { T2DM patients } \\
\quad(\mathrm{n}=243)\end{array}$ \\
\hline Mean age in years $\pm \mathrm{SD}$ & $31.5 \pm 11.6$ & $52.4 \pm 10.4$ \\
\hline Male gender & $43(52.4)$ & $144(59.3)$ \\
\hline $\begin{array}{l}\text { Mean diabetes duration in } \\
\text { years } \pm \text { SD }\end{array}$ & $13.5 \pm 8.7$ & $14.5 \pm 7.5$ \\
\hline $\begin{array}{l}\text { Mean insulin duration in } \\
\text { years } \pm \text { SD }\end{array}$ & $12.6 \pm 8.6$ & $6.8 \pm 6.0$ \\
\hline Mean $\mathrm{HbAlc} \% \pm \mathrm{SD}$ & $8.6 \pm 1.9$ & $8.6 \pm 1.6$ \\
\hline Mean FBG in $\mathrm{mmol} / \mathrm{L} \pm \mathrm{SD}$ & $7.7 \pm 3.7$ & $7.7 \pm 2.4$ \\
\hline Mean PPG in $\mathrm{mmol} / \mathrm{L} \pm \mathrm{SD}$ & $9.6 \pm 3.5$ & $11.1 \pm 3.9$ \\
\hline Mean BMI in $\mathrm{kg} / \mathrm{m}^{2} \pm \mathrm{SD}$ & $25.5 \pm 4.5$ & $31.4 \pm 6.2$ \\
\hline \multicolumn{3}{|l|}{ Previous illnesses, \%* } \\
\hline Neuropathy & 15.9 & 44 \\
\hline Retinopathy & 19.5 & 32.1 \\
\hline Nephropathy & 9.8 & 21 \\
\hline PVD & 4.9 & 10.7 \\
\hline Angina & 1.2 & 16.5 \\
\hline Myocardial infarction & 0 & 11.9 \\
\hline None & 63.4 & 39.1 \\
\hline \multicolumn{3}{|l|}{ Oral antidiabetic medications } \\
\hline$\alpha$-glucosidase inhibitors & $1(1.2)$ & $7(2.9)$ \\
\hline Metformin & $9(11)$ & $169(69.5)$ \\
\hline DPP-4 inhibitors & $5(6.1)$ & $115(47.3)$ \\
\hline GLP-1 analogues & $1(1.2)$ & $18(7.4)$ \\
\hline Metiglinides/glinides & $0(0)$ & $3(1.2)$ \\
\hline SGLT2 inhibitors & $1(1.2)$ & $23(9.5)$ \\
\hline Sulfonylureas & $2(2.4)$ & $68(28)$ \\
\hline Thiazolidinediones & $0(0)$ & $8(3.3)$ \\
\hline Other & $1(1.2)$ & $12(4.9)$ \\
\hline None & $68(82.9)$ & $30(12.3)$ \\
\hline \multicolumn{3}{|l|}{ Insulin regimen $^{+}$} \\
\hline SA & $2(4)$ & $7(2.2)$ \\
\hline LA & $0(0)$ & $77(24.1)$ \\
\hline Premixed & $6(7.3)$ & $73(30)$ \\
\hline Both SA and LA & $62(75.6)$ & $92(37.9)$ \\
\hline Both SA and premixed & $2(2.4)$ & $7(2.9)$ \\
\hline Both LA and premixed & $1(1.2)$ & 4. (1.6) \\
\hline \multicolumn{3}{|l|}{ Ability to self-assess BG levels ${ }^{\dagger}$} \\
\hline Yes & $72(87.8)$ & $221(90.9)$ \\
\hline No & $3(3.7)$ & $18(7.4)$ \\
\hline Unsure & $6(7.3)$ & $4(1.6)$ \\
\hline
\end{tabular}

T1DM = type 1 diabetes mellitus; $T 2 D M=$ type 2 diabetes mellitus; $S D=$ standard deviation; $H b A 1 c=$ glycated haemoglobin; $F B G=$ fasting blood glucose; $P P G=$ post-prandial glucose; $B M I=$ body mass index; $P V D=$ peripheral vascular disease; $D P P=$ dipeptidyl peptidase; $G L P=$ glucagon-like peptide; $S G L T 2$ = sodium-glucose cotransporter-2; $S A=$ short-acting; LA = long-acting. "Percentages do not add up to $100 \%$ as some patients may have had more than one illness. ${ }^{\dagger}$ Percentages are based on the number of patients with available data. caemic control. Awareness of hypoglycaemia was evaluated according to the patients' responses to the question 'Do you have symptoms when you have low sugar levels?', in which the response 'usually' denoted impaired awareness and 'occasionally' or 'never' denoted severely impaired awareness. Fear of hypoglycaemia was self-assessed by patients on a scale of $0-10$, where 0 denoted 'not afraid at all' and 10 was 'absolutely terrified.' Glycaemic control was determined by baseline HbA1c measurements, with percentages of $>9 \%, 7-9 \%$ and $<7 \%$ indicating poor, suboptimal and good glycaemic control, respectively. Comprehensive details of the design of the IO-HAT study and the procedures used for the assessment of hypoglycaemia have been previously reported by Emral et al. ${ }^{11}$

The percentages of patients experiencing at least one hypoglycaemic event during the four-week prospective period were calculated along with 95\% confidence intervals (CIs). Rates of hypoglycaemia were deemed equivalent in the retrospective and prospective periods according to two-sided statistical tests with the level of statistical significance set at $P \leq 0.050$. The IRs of hypoglycaemia were calculated as the total number of events per patient-year (PY) divided by the total follow-up time in PYs along with 95\% CIs. The difference in the reported incidence of hypoglycaemia was calculated using a negative binomial regression model, including a single binary covariate for two periods (four weeks before baseline and four weeks after baseline), specifying a logged exposure time as the offset term and using robust standard error to adjust for repeated measurements and the potential dependence between patients sharing the same site (site-level clustering).

This study was approved by the local ethics committee at each patient care centre, including the Al Qassimi Hospital Research \& Ethics Committee, Sharjah (\#154/2014-09-21), the Dubai Scientific Research Ethics Committee, Dubai (\#DSREC-12/2014-03), the Institutional Review Board/Research Ethics Committee of Sheikh Khalifa Medical City, Abu Dhabi (\#REC-05.02.2015 RS-352) and the Gulf Medical University Ethics Committee, Ajman (\#NovoNordisk/1/30032015). All study procedures were conducted in accordance with the guidelines of the International Society for Pharmacoepidemiology and the ethical standards of the revised Declaration of Helsinki. ${ }^{14}$ All patients provided informed consent prior to their participation in the study.

\section{Results}

A total of 325 patients were enrolled in the study at baseline, of which 82 (25.2\%) had T1DM and 243 (74.8\%) had T2DM. Overall, the mean age of patients with T2DM was higher than those with T1DM $(52.4 \pm 10.4$ years versus $31.5 \pm 11.6$ years). In addition, the mean duration 


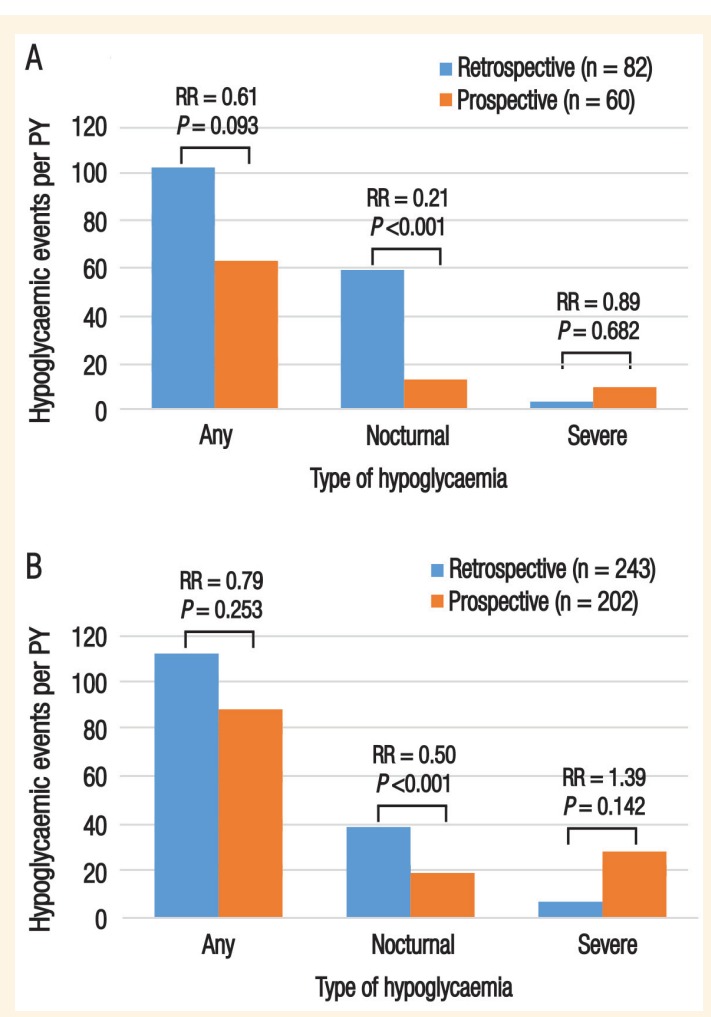

Figure 2: Incidence rates of hypoglycaemia among insulin-treated patients with (A) type 1 and (B) type 2 diabetes mellitus in the United Arab Emirates $(\mathrm{N}=325)$. Hypoglycaemic events were assessed retrospectively over a four-week and six-month period (for nocturnal/ non-severe and severe hypoglycaemia, respectively) and prospectively over a four-week period.

$P Y=$ patient-year $; R R=$ risk ratio.

of insulin use was shorter among patients with T2DM compared to those with T1DM $(6.8 \pm 6.0$ years versus $12.6 \pm 8.6$ years). However, mean baseline HbA1c percentages were similar in both groups $(8.6 \pm 1.6 \%$ versus $8.6 \pm 1.9 \%$ ) [Table 1]. A total of 262 patients completed the second part of the questionnaire after the prospective period had elapsed. Of these, 60 (22.9\%) had T1DM and 202 (77.1\%) had T2DM.

Nearly all patients with T1DM (95\%; 95\% CI: 86.1-99.0\%) and T2DM (91.9\%; 95\% CI: 87.1-95.3\%) reported at least one hypoglycaemic event during the prospective period. In contrast, $71.4 \%$ (95\% CI: $60.0-81.2 \%$ ) of patients with T1DM and 56.3\% (95\% CI: 49.7-62.7\%) of patients with T2DM experienced hypoglycaemic events in the retrospective period. Nocturnal hypoglycaemic events were reported in 56.7\% (95\% CI: 44.0-68.8\%) and 35.6\% (95\% CI: 29.3-42.3\%) of patients with T1DM and T2DM, respectively, in the retrospective period. During the prospective period, 43.6\% (95\% CI: $30.3-57.7 \%$ ) of patients with T1DM and $33.5 \%$ (95\% CI: $26.8-40.7 \%$ ) of patients with T2DM reported nocturnal hypoglycaemic events. Severe hypoglycaemic events were experienced by $39.5 \%$ (95\% CI: 28.4-51.4\%) and 44\% (95\% CI: $37.6-50.6 \%$ ) of patients
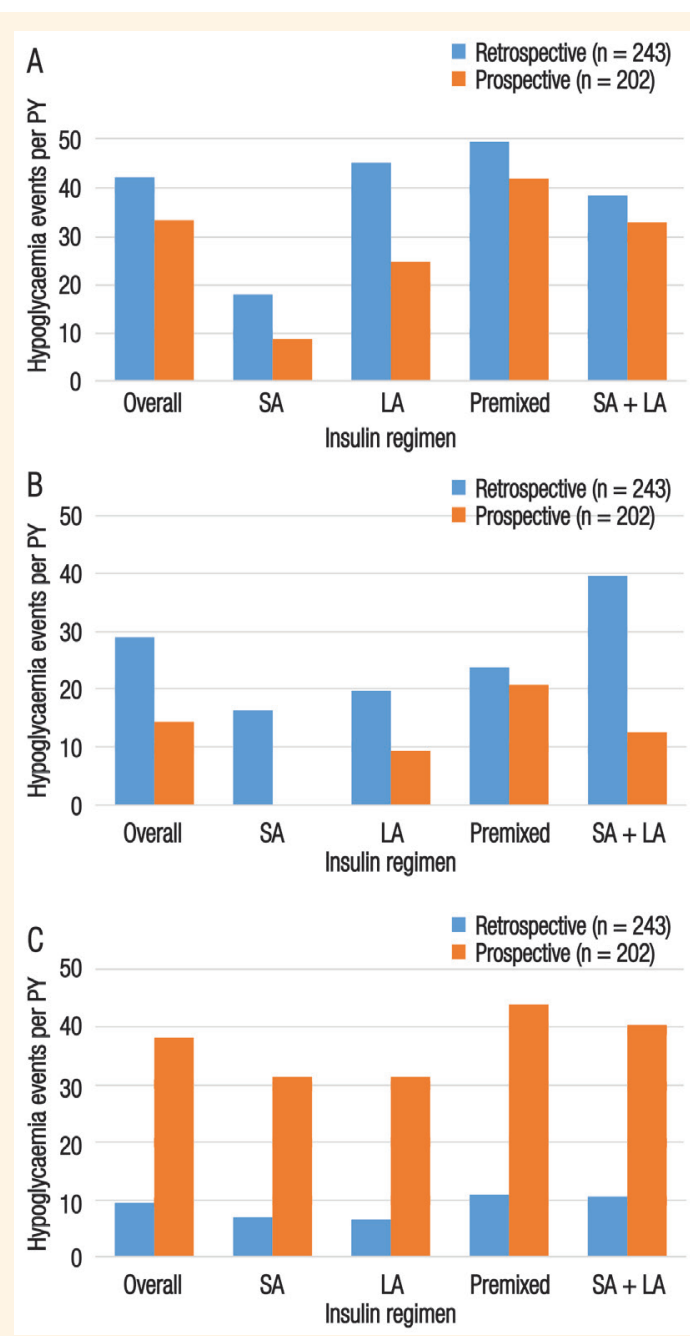

Figure 3: Incidence rates of (A) any, (B) nocturnal and (C) severe hypoglycaemia according to insulin regimen among patients with type 2 diabetes mellitus in the United Arab Emirates $(\mathrm{N}=243)$. Hypoglycaemic events were assessed retrospectively over a four-week and sixmonth period (for nocturnal/non-severe and severe hypoglycaemia, respectively) and prospectively over a four-week period.

$P Y=$ patient-year; $S A$ = short-acting; $L A=$ long-acting.

with T1DM and T2DM, respectively, in the retrospective period. In the prospective period, $61.7 \%$ (95\% CI: $54.4-68.5 \%$ ) of T2DM patients and 36.7\% (95\% CI: 24.6-50.1\%) of T1DM patients reported severe hypoglycaemic events.

Among patients with T1DM, the IR of any hypoglycaemic event was higher in the retrospective period than the prospective period, although this difference was not significant (102.8 events per PY, 95\% CI: 94.8-11.3 events per PY versus 63.1 events per PY, 95\% CI: 56.0-70.7 events per PY; $P=0.093$ ). The IR of nocturnal hypoglycaemia among patients with T1DM was significantly higher in the retrospective period compared to the prospective period (59.2 events per PY, 95\% CI: 52.7-66.2 events per PY versus 12.6 events per PY, 95\% CI: 9.4-16.4 events per PY; $P<0.001)$. However, 
Table 2: Actions and perceptions following hypoglycaemic events among insulin-treated patients with type 1 and type 2 diabetes mellitus in the United Arab Emirates $(\mathrm{N}=325)$

\begin{tabular}{|c|c|c|c|c|}
\hline & \multicolumn{4}{|c|}{ n $(\%)^{*}$} \\
\hline & \multicolumn{2}{|c|}{$\begin{array}{l}\text { T1DM patients } \\
\quad(\mathbf{n}=82)\end{array}$} & \multicolumn{2}{|c|}{$\begin{array}{l}\text { T2DM patients } \\
\quad(\mathrm{n}=243)\end{array}$} \\
\hline & RT & PT & RT & PT \\
\hline $\begin{array}{l}\text { Action following } \\
\text { event }\end{array}$ & $\mathrm{n}=82$ & $n=60$ & $\mathrm{n}=243$ & $\mathrm{n}=202$ \\
\hline $\begin{array}{l}\text { Consulted their } \\
\text { doctor/nurse }\end{array}$ & $46(56.1)$ & $27(45)$ & $141(58)$ & $93(46)$ \\
\hline $\begin{array}{l}\text { Required } \\
\text { medical } \\
\text { assistance }\end{array}$ & $46(56.1)$ & $27(45)$ & $146(60.1)$ & $94(46.5)$ \\
\hline $\begin{array}{l}\text { Increased caloric } \\
\text { intake }\end{array}$ & $21(25.6)$ & $15(25)$ & 63 (25.9) & $55(27.2)$ \\
\hline $\begin{array}{l}\text { Avoided physical } \\
\text { exercise }\end{array}$ & 11 (13.4) & $5(8.3)$ & $48(19.8)$ & $44(21.8)$ \\
\hline $\begin{array}{l}\text { Reduced insulin } \\
\text { dose }\end{array}$ & $22(26.8)$ & $24(40)$ & $62(25.5)$ & $65(32.2)$ \\
\hline $\begin{array}{l}\text { Skipped insulin } \\
\text { injections }\end{array}$ & 15 (18.3) & $10(16.7)$ & $54(22.2)$ & $38(18.8)$ \\
\hline $\begin{array}{l}\text { Increased BG } \\
\text { monitoring }\end{array}$ & 45 (54.9) & $31(51.7)$ & $88(36.2)$ & $64(31.7)$ \\
\hline $\begin{array}{l}\text { Perceivedimpact } \\
\text { of event on the } \\
\text { medical system }\end{array}$ & $n=82$ & $n=60$ & $\mathrm{n}=243$ & $\mathrm{n}=202$ \\
\hline $\begin{array}{l}\text { Required } \\
\text { hospital } \\
\text { admission }\end{array}$ & $9(13.6)$ & $3(5.2)$ & $8(4.3)$ & $1(0.5)$ \\
\hline $\begin{array}{l}\text { Added telephone } \\
\text { contacts }\end{array}$ & $11(16.7)$ & $5(8.6)$ & $30(16.1)$ & $39(20.1)$ \\
\hline $\begin{array}{l}\text { Perceived } \\
\text { impact of event } \\
\text { on work/studies }^{+}\end{array}$ & $n=63$ & $n=46$ & $\mathrm{n}=143$ & $\mathrm{n}=126$ \\
\hline Took leave & $17(27)$ & $5(10.9)$ & $16(11.2)$ & $8(6.3)$ \\
\hline Arrived late & $11(17.5)$ & $6(13)$ & $13(9.1)$ & $7(5.6)$ \\
\hline Left early & $10(15.9)$ & $4(8.7)$ & $9(6.3)$ & $6(4.8)$ \\
\hline
\end{tabular}

$R T$ = retrospective; $P T$ = prospective; T1DM = type 1 diabetes mellitus; $T 2 D M=$ type 2 diabetes mellitus; $B G=$ blood glucose. ${ }^{* P e r c e n t a g e s}$ are based on the number of patients with evaluable data. ${ }^{\dagger}$ Only applicable to patients who worked/studied.

the IR of severe hypoglycaemia in this group showed a non-significant increase in the prospective period compared to the retrospective period (9.4 events per PY, 95\% CI: 6.8-12.6 events per PY versus 3.2 events per PY, 95\% CI: $2.6-3.8$ events per PY; $P=0.682$ ) [Figure 2A].

Similarly, the IR of any hypoglycaemic events among patients with T2DM was slightly higher in the retrospective period compared to the prospective period (42.2 events per PY, 95\% CI: 39.2-45.2 events per PY versus 33.3 events per PY, 95\% CI: 30.4-36.3 events per PY). In contrast, the IR of severe hypoglycaemia was higher in the prospective period compared to the retrospective period (10.6 events per
PY, 95\% CI: 9.0-12.4 events per PY versus 2.6 events per PY, 95\% CI: $2.3-2.9$ events per PY); nevertheless, both of these differences were non-significant $(P=0.253$ and 0.142 , respectively). As with the T1DM patients, the IR of nocturnal hypoglycaemia among patients with T2DM was significantly higher in the retrospective period compared to the prospective period (14.5 events per PY, 95\% CI: 12.7-16.4 events per PY versus 7.2 events per PY, 95\% CI: 5.9-8.7 events per PY; $P<0.001$ ) [Figure 2B].

The IRs of any, nocturnal and severe hypoglycaemic events were calculated according to insulin regimens. For T1DM patients, the greatest IR of any hypoglycaemic events was observed with the use of a premixed insulin regimen in the prospective period (208.7 events per PY). The greatest IR of nocturnal hypoglycaemic events occurred among patients using a combination of short- and long-acting insulin regimens in the retrospective period (72.1 events per PY). For severe hypoglycaemic events, the greatest IR was observed among patients undertaking a long-acting insulin regimen in the prospective period (58.7 events PPY). The IRs for all types of hypoglycaemic events by insulin regimen for patients with T2DM in both the retrospective and prospective periods is presented in Figure 3.

No correlation was found between the percentage of patients experiencing hypoglycaemic events and glycaemic control in the prospective and retrospective periods. Among patients with T1DM, the majority (73.7\%) of any hypoglycaemic events in the four-week retrospective period was experienced by patients with suboptimal glycaemic control; however, the proportion of patients experiencing any hypoglycaemic events was higher in those with poor glycaemic control compared to those with good glycaemic control (63.6\% versus 61.5\%). Among patients with T2DM, $64.8 \%$ of patients with poor glycaemic control, $54.5 \%$ with good glycaemic control and 53\% with suboptimal glycaemic control experienced any hypoglycaemic events.

In terms of their perceptions of how hypoglycaemic events impacted the medical system, $5.2 \%$ versus $13.6 \%$ of T1DM patients and $0.5 \%$ versus $4.3 \%$ of $\mathrm{T} 2 \mathrm{DM}$ patients reported that the event required hospital admission in the prospective period compared to the retrospective period. In addition, T1DM patients more frequently reported that the event resulted in additional telephone contacts retrospectively (16.7\% versus $8.6 \%)$, while more T2DM patients reported this prospectively (20.1\% versus $16.1 \%)$. Furthermore, more patients with T1DM undertook increased BG monitoring following the event compared to patients with T2DM in both the retrospective (54.9\% versus $36.2 \%$ ) and prospective (51.7\% versus $31.7 \%)$ periods. In the retrospective period, fewer patients with T2DM compared to those 
Table 3: Knowledge, awareness and fear of hypoglycaemia among insulin-treated patients with type 1 and type 2 diabetes mellitus in the United Arab Emirates $(\mathrm{N}=325)$

\begin{tabular}{lcc} 
& \multicolumn{2}{c}{$\mathbf{n}(\%)$} \\
& $\begin{array}{c}\text { T1DM patients } \\
(\mathbf{n}=\mathbf{8 2})\end{array}$ & $\begin{array}{c}\text { T2DM patients } \\
(\mathbf{n}=243)\end{array}$ \\
$\begin{array}{l}\text { Knowledge of hypo- } \\
\text { glycaemia at baseline* }\end{array}$ & $69(84.2)$ & $193(79.4)$ \\
$\begin{array}{l}\text { Definition of a hypoglycaemic event } \\
\text { Symptoms }\end{array}$ & $119(49)$ \\
BG measurements & $59(47.6)$ & $7(2.9)$ \\
$\begin{array}{l}\text { Either symptoms or } \\
\text { BG measurements }\end{array}$ & $15(18.3)$ & $26(10.7)$ \\
$\begin{array}{l}\text { Both symptoms and } \\
\text { BG measurements }\end{array}$ & $20(24.4)$ & $71(29.2)$ \\
Awareness of hypoglycaemia & \\
Normal & $49(59.8)$ & $133(54.7)$ \\
Impaired & $32(39)$ & $87(35.8)$ \\
Severely impaired & $1(1.2)$ & $14.8 \pm 3.7$ \\
$\begin{array}{l}\text { Mean fear of } \\
\text { hypoglycaemia } \pm \text { SD }\end{array}$ & $4.7 \pm 3.6$ & \\
\hline
\end{tabular}

T1DM = type 1 diabetes mellitus; T2DM = type 2 diabetes mellitus; $B G=$ blood glucose; $S D=$ standard deviation.

*Prior to the first self-assessment questionnaire being administered. ${ }^{\dagger}$ Excluding nine patients with T2DM for whom data for this category were unavailable. ${ }^{\neq}$Scored on a scale of $0-10$, where 0 denoted not afraid at all' and 10 was 'absolutely terrified'.

with T1DM reported that hypoglycaemic events resulted in their absence (11.2\% versus $27 \%)$, late arrival (9.1\% versus $17.5 \%)$ or early departure (6.3\% versus $15.9 \%)$ from work or studies [Table 2].

Many patients with T1DM (84.2\%) and T2DM (79.4\%) had baseline knowledge of hypoglycaemia before being provided with the definition in the first part of the questionnaire. The number of patients defining hypoglycaemic events based on symptoms alone or in conjunction with BG measurements was comparable in both the T1DM and T2DM groups (47.6\% versus $49 \%$ and $24.4 \%$ versus $29.2 \%$, respectively). However, a small proportion of both T1DM and T2DM patients used only BG measurements to define hypoglycaemia (6.1\% versus 2.9\%). Fewer patients with T1DM had severely impaired awareness of hypoglycaemia compared to T2DM patients (1.2\% versus $5.8 \%)$. The mean fear of hypoglycaemia score was comparable between the two groups ( $4.7 \pm 3.6$ versus $4.8 \pm 3.7$ ) [Table 3]

\section{Discussion}

According to the International Diabetes Federation, 425 million people had diabetes mellitus (DM) in 2017 and this number is expected to reach 629 million by $2045 .{ }^{15}$ The UAE has one of the world's highest prevalence rates of DM (15.4\%), with $40 \%$ of those over the age of 60 years suffering from the condition and 2.7 new cases of T1DM diagnosed per 100,000 children and adolescents annually. ${ }^{16-19}$ By 2045, it is predicted that $23.4 \%$ of the population between 20-79 years old in the UAE will have DM. ${ }^{17,18}$ Therefore, identifying the incidence of hypoglycaemic events is paramount in order to determine disease burden. However, recent studies have detected higher rates of hypoglycaemia in real-world settings when compared with the results of clinical trials. ${ }^{5,8,20}$ This may be a result of the stringent methodological and design constraints of RCTs, as well as the restricted selection of patients, uniform treatment approach and insufficient BG monitoring which limits the generalisability of such findings to routine clinical practice. ${ }^{9-12}$

As part of the larger IO-HAT study, the current study analysed self-reported rates of hypoglycaemic events among a cohort of insulin-treated DM patients from patient care centres in the UAE. ${ }^{11}$ Although higher rates of any or nocturnal hypoglycaemic events were reported in the current study during the retrospective period compared to the prospective period for both T1DM and T2DM patients, higher rates of severe hypoglycaemic events were reported prospectively in both periods; this may indicate that severe hypoglycaemic events were underreported by participants during the retrospective period. Gubitosi-Klug et al. similarly reported a higher incidence of severe hypoglycaemia in the prospective period among patients with T1DM. ${ }^{21}$

In the current study, the level of knowledge of the definition and symptoms of hypoglycaemia was similar to previously reported findings among diabetic individuals. ${ }^{19,22}$ This may be because such patients have individualised BG targets, greater experience with BG monitoring or have received patient education on this topic. ${ }^{23}$ Fear of hypoglycaemia can have major clinical repercussions for DM management. However, in the current study, low fear of hypoglycaemia was reported among both T1DM and T2DM patients, possibly due to adequate hypoglycaemia awareness and glycaemic control. ${ }^{24}$ Nevertheless, patients stated that hypoglycaemic events often negatively impacted their work or studies, with T1DM patients in particular more frequently reporting that such events resulted in absences, arriving late or leaving early compared to T1DM patients. Previous research also supports the notion that hypoglycaemia restricts social or functional activities, increases absenteeism, impairs punctuality and reduces productivity. ${ }^{25,26}$

Previous studies have shown that all forms of hypoglycaemia are independent of levels of glycaemic control..$^{27,28}$ Increased hypoglycaemic events in patients 
with higher HbA1c levels may reflect poor self-care behaviours as well as aggressive efforts to improve their glycaemic control. Lash et al. advocate for increasing hypoglycaemia awareness, patient education and shared decision-making and the adoption of risk assessment and clinical decision-making support tools to support management of the condition. ${ }^{29}$

The current study is subject to certain limitations. During the enrolment of eligible patients, the possibility of volunteer bias could not be excluded. In addition, due to the retrospective design of the study, self-reported rates of hypoglycaemia may have been affected by recall bias; for example, patients may have under- or overreported severe hypoglycaemic events based on the definition alone, regardless of the severity of their symptoms or BG measurements. ${ }^{3}$ In addition, there may have been an overestimation in reported events while adjusting for recall bias, as reported rates of hypoglycaemic events were higher in patient diaries compared to their responses to the second part of the self-assessment questionnaire. Nevertheless, precautions were taken to ensure that rates of hypoglycaemia were not overreported by following the guidelines of the International Society for Pharmacoepidemiology. ${ }^{14}$

\section{Conclusion}

To the best of the authors' knowledge, this is the first patient-reported dataset of hypoglycaemic events among the UAE cohort of the IO-HAT study. These findings highlight the high prevalence and incidence of hypoglycaemia among insulin-treated patients with DM and the potential impact of the condition on productivity, health and healthcare resource utilisation. Patient education and personalised glycaemic goals may help to lower the incidence of all forms of hypoglycaemia in this population, thus reducing associated costs to the healthcare system.

\section{ACKNOWLEDGEMENTS}

The statistical analysis of the data was performed by Parexel International (Waltham, Massachusetts, USA). Medical writing and submission support was provided by Cognizant Technology Solutions Pvt. Ltd. (Pune, Maharashtra, India). Novo Nordisk A/S Pharmaceutical Company (Bagsværd, Denmark) was involved in the study conception and design, data collection, statistical analysis and interpretation and provided the materials, patients and resources. The decision to submit the article for publication was made by Novo Nordisk A/S Pharmaceutical Company.

\section{CONFLICT OF INTEREST}

Professor Salah Abusnana and Dr Salem A. Beshyah received research grants and financial support for the submitted work from Novo Nordisk A/S Pharmaceutical Company. Professor Salah Abusnana, Dr Salem A. Beshyah, Dr Mahir Jallo, Dr Rima Tahhan and Dr Ravi Arora received payments for lectures and continuing medical education events as speakers. Dr Salem A. Beshyah, Dr Mahir Jallo and Dr Ravi Arora received reimbursements for travel and accommodation expenses for national and international conferences. Dr Hazem Aly and Dr Sagar Singhal are currently employed as medical advisors by the UAE branch of Novo Nordisk A/S Pharmaceutical Company.

\section{FUNDING}

This study was funded by Novo Nordisk A/S Pharmaceutical Company, Bagsværd, Denmark (HAT-IO \#INS-4177).

\section{References}

1. American Diabetes Association. American Diabetes Association issues hypoglycemia position statement: Levels to be reported during clinical trials defined, based upon recommendations by International Hypoglycemia Study Group. From: www.diabetes. org/newsroom/press-releases/2016/ada-issues-hypoglycemiaposition-statement.html Accessed: Jul 2018.

2. Shafiee G, Mohajeri-Tehrani M, Pajouhi M, Larijani B. The importance of hypoglycemia in diabetic patients. J Diabetes Metab Disord 2012; 11:17. https://doi.org/10.1186/2251-658111-17.

3. Kalra S, Mukherjee JJ, Venkataraman S, Bantwal G, Shaikh S, Saboo B, et al. Hypoglycemia: The neglected complication. Indian J Endocrinol Metab 2013; 17:819-34. https://doi.org/10.4103/2 230-8210.117219.

4. Meng J, Casciano R, Lee YC, Stern L, Gultyaev D, Tong L, et al. Effect of diabetes treatment-related attributes on costs to type 2 diabetes patients in a real-world population. J Manag Care Spec Pharm 2017; 23:446-52. https://doi.org/10.18553/ jmcp.2017.23.4.446.

5. Edridge CL, Dunkley AJ, Bodicoat DH, Rose TC, Gray LJ, Davies MJ, et al. Prevalence and incidence of hypoglycaemia in 532,542 people with type 2 diabetes on oral therapies and insulin: A systematic review and meta-analysis of populationbased studies. PLoS One 2015; 10:e0126427. https://doi.org/1 0.1371/journal.pone.0126427.

6. Aronson R, Goldenberg R, Boras D, Skovgaard R, Bajaj H. The Canadian Hypoglycemia Assessment Tool Program: Insights into rates and implications of hypoglycemia from an observational study. Can J Diabetes 2018; 42:11-17. https://doi.org/1 0.1016/j.jcjd.2017.01.007.

7. Kulzer B, Seitz L, Kern W. Real-world patient-reported rates of non-severe hypoglycaemic events in Germany. Exp Clin Endocrinol Diabetes 2014; 122:167-72. https://doi.org/10.105 5/s-0033-1363688.

8. Elliott L, Fidler C, Ditchfield A, Stissing T. Hypoglycemia event rates: A comparison between real-world data and randomized controlled trial populations in insulin-treated diabetes. Diabetes Ther 2016; 7:45-60. https://doi.org/10.1007/s13300-0160157-z. 
9. UK Hypoglycaemia Study Group. Risk of hypoglycaemia in types 1 and 2 diabetes: Effects of treatment modalities and their duration. Diabetologia 2007; 50:1140-7. https://doi.org/10.100 7/s00125-007-0599-y.

10. Nathan DM; DCCT/EDIC Research Group. The diabetes control and complications trial/epidemiology of diabetes interventions and complications study at 30 years: Overview. Diabetes Care 2014; 37:9-16. https://doi.org/10.2337/dc13-2112.

11. Emral R, Pathan F, Cortés CA, El-Hefnawy MH, Goh SY, Gómez AM, et al. Self-reported hypoglycemia in insulin-treated patients with diabetes: Results from an international survey on 7289 patients from nine countries. Diabetes Res Clin Pract 2017; 134:17-28. https://doi.org/10.1016/j.diabres.2017.07.031.

12. Khunti K, Alsifri S, Aronson R, Cigrovski Berković M, Enters-Weijnen C, Forsén T, et al. Rates and predictors of hypoglycaemia in 27585 people from 24 countries with insulintreated type 1 and type 2 diabetes: The global HAT study. Diabetes Obes Metab 2016; 18:907-15. https://doi.org/10.1111/ dom.12689.

13. Workgroup on Hypoglycemia, American Diabetes Association. Defining and reporting hypoglycemia in diabetes: A report from the American Diabetes Association Workgroup on Hypoglycemia. Diabetes Care 2005; 28:1245-9. https://doi.org/10.2 337/diacare.28.5.1245.

14. International Society for Pharmacoepidemiology. Guidelines for good pharmacoepidemiology practices (GPP). Pharmacoepidemiol Drug Saf 2008; 17:200-8. https://doi.org/10.1002/ pds.1471.

15. International Diabetes Federation. IDF diabetes atlas: Fifth edition. From: diabetesatlas.org/resources/previous-editions.html Accessed: Jul 2018

16. International Diabetes Federation. IDF diabetes atlas 8th edition 2017: Regional fact sheets - Middle East and North Africa. From: diabetesatlas.org/resources/2017-atlas.html Accessed: Jul 2018.

17. United Health Group. Diabetes in the United Arab Emirates: Crisis or opportunity? From: www.unitedhealthgroup.com/ / media/UHG/PDF/2010/UNH_WorkingPaperDiabetesUAE. ashx?la=en Accessed: Jul 2018.

18. Razzak HA, Harbi A, Shelpai W, Qawas A. Epidemiology of diabetes mellitus in the United Arab Emirates. Curr Diabetes Rev 2018; 14:542-9. https://doi.org/10.2174/157339981366617 0920152913 .

19. Hamoudi NM, Al Ayoubi ID, Al Sharbatti S, Shirwaikar AA. Awareness of diabetes mellitus among UAE non-diabetic population in Ajman and Ras Alkhaimah. J Appl Pharm Sci 2012; 2:50-3. https://doi.org/10.7324/japs.2012.2410
20. Cariou B, Fontaine P, Eschwege E, Lièvre M, Gouet D, Huet D, et al. Frequency and predictors of confirmed hypoglycaemia in type 1 and insulin-treated type 2 diabetes mellitus patients in a real-life setting: Results from the DIALOG study. Diabetes Metab 2015; 41:116-25. https://doi.org/10.1016/j.diabet.2 014.10.007.

21. Gubitosi-Klug RA, Braffett BH, White NH, Sherwin RS, Service FJ, Lachin JM, et al. Risk of severe hypoglycemia in type 1 diabetes over 30 years of follow-up in the DCCT/EDIC Study. Diabetes Care 2017; 40:1010-16. https://doi.org/10.2337/dc162723.

22. Shriraam V, Mahadevan S, Anitharani M, Jagadeesh NS, Kurup SB, Vidya TA, et al. Knowledge of hypoglycemia and its associated factors among type 2 diabetes mellitus patients in a tertiary care hospital in South India. Indian J Endocrinol Metab 2015; 19:378-82. https://doi.org/10.4103/2230-8210.152779.

23. Martín-Timón I, Del Cañizo-Gómez FJ. Mechanisms of hypoglycemia unawareness and implications in diabetic patients. World J Diabetes 2015; 6:912-26. https://doi.org/10.4239/wjd. v6.i7.912.

24. Wild D, von Maltzahn R, Brohan E, Christensen T, Clauson P, Gonder-Frederick L. A critical review of the literature on fear of hypoglycemia in diabetes: Implications for diabetes management and patient education. Patient Educ Couns 2007; 68:10-15. https://doi.org/10.1016/j.pec.2007.05.003.

25. Hassoun AA, Abdella N, Arouj MA, Awadi FA, Futaisi AA, Lamki MA, et al. Driving and diabetes mellitus in the Gulf Cooperation Council countries: Call for action. Diabetes Res Clin Pract 2015; 110:91-4. https://doi.org/10.1016/j.diabres.20 15.08.002.

26. Lopez JM, Annunziata K, Bailey RA, Rupnow MF, Morisky DE. Impact of hypoglycemia on patients with type 2 diabetes mellitus and their quality of life, work productivity, and medication adherence. Patient Prefer Adherence 2014; 8:683-92. https:// doi.org/10.2147/PPA.S58813.

27. Cox DJ, Gonder-Frederick L, Ritterband L, Clarke W, Kovatchev BP. Prediction of severe hypoglycemia. Diabetes Care 2007; 30:1370-3. https://doi.org/10.2337/dc06-1386.

28. Murata GH, Hoffman RM, Shah JH, Wendel CS, Duckworth WC. A probabilistic model for predicting hypoglycemia in type 2 diabetes mellitus: The Diabetes Outcomes in Veterans Study (DOVES). Arch Intern Med 2004; 164:1445-50. https://doi. org/10.1001/archinte.164.13.1445

29. Lash RW, Lucas DO, Illes J. Preventing hypoglycemia in type 2 diabetes. J Clin Endocrinol Metab 2018; 103:1265-8. https:// doi.org/10.1210/jc.2017-02804. 